\title{
Critical Appraisal of Parameters for Successful Implementation of BRTS in India
}

\author{
Mustafa Kapadia', Satyaki Sarkar² , Bimal Chandra Roy², Rajan Chandra Sinha \\ ${ }_{1}^{1}$ Associate Architect \& Planner, Kapadia \& Associate, 13 Mehboob Plaza, Evergreen Chock, Bejnath Para, Raipur 492001, India \\ 2 Department of Architecture and Planning, Birla Institute of Technology, Mesra, Ranchi 835215, India \\ * Corresponding author, e-mail: satyakisarkar@bitmesra.ac.in
}

Received: 22 May 2020, Accepted: 13 August 2020, Published online: 16 February 2022

\begin{abstract}
Bus Rapid Transit System (BRTS) is establishing itself as a new and sustainable solution to mass transit against the conventional transit systems in many cities across the globe as well as in India. Different BRTSs have adopted various case-specific solutions to make the system contextual to the place, user-friendly, strategic, technologically advanced, and ecologically sustainable. In most cases, the most favoured solution is governed by aspects related to available infrastructure, budgetary allocations, demand and behavioral patterns of passengers, and areas of focus. The paper makes a critical appraisal of various parameters contributing to the implementation of BRTS services across the world and applicability of the same in India. It also deals with how the application of a new transportation system affects the surrounding area and with the resulting various social and physical impacts. As a conclusion, this paper establishes that successful BRTS must combine proper station design, track design, maintained vehicles and running ways with backup infrastructure, educated and updated drivers and workforce, public cautiousness, and system-backed information technology. Further, it concludes that the institutional framework needs revamping in Indian scenario for successful implementation of BRTS projects.
\end{abstract}

Keywords

BRTS, comparative methodology, Indian cities, infrastructure

\section{Introduction}

The transportation sector today is undergoing rapid transformation. Many cities of developing countries experiencing rapid urbanization impregnated by transportation problems as resultant development is too fast and uncontrolled. The transportation sector, the central spine of progress today, is often characterized by ever-increasing commuter demand, inadequate and obsolete infrastructure, problems of growing energy consumption, air pollution, health issues, and road safety. Developing countries which are primarily impregnated by challenges of unplanned growth and urbanization have started introducing mass rapid transport systems including commuter rails and buses to respond to the problems and make the process sustainable. Various modes of urban transportation, including Bus Rapid Transit System (BRTS), Metro and monorail, Bicycle-sharing, usage of CNG fuels are slowly becoming an integral part of today's sustainable urban transportation system.

\section{Background of the study}

There is a growing demand to adopt a responsive mode of conveyance which is sustainable and can respond to the ever-increasing crisis of congestion, air pollution, and accident prevention. BRTS will contribute to the reduction of demand through increasing capacity, flexibility, and reliability. It will create environment-friendly transport modes that emphasize the use of energy, and pollution, creating a better delivery mechanism through an increase of access, minimizing accidents, and reducing congestion. The demand stem from the rapid decrease in Delhi's air quality, massive congestion on roads, and high traffic time. However, most of the sustainable modes of transportation across the world have survived their time as it involved progressive governmental policies, planning processes, and control strategies efficiencies. Promotion of such vehicles with significant publicity has resulted in users to shift their mode of conveyance from private to public. Hence cities with more extensive road structure, increasing passenger demand, and looking for a sustainable tomorrow 
have started accommodating various modes of sustainable transportation systems within its wings.

\section{Literature review}

There is a need for a clean green transport sector in today's world marked by safer mobility, passenger-friendly environment that may aim to reduce the menace of GHG gases, traffic accidents, and decongest urban roads. Garg et al. (2017) estimated that the transport sector alone contributed to $11.6 \%$ of $\mathrm{CO}_{2}$ emission over the last two decades. Imam (2012) investigated twenty cases of BRTSS in fifteen different countries in Europe and concluded that BRTS systems considerably reduced $\mathrm{CO}_{2}$ emission for most situations. The World Health Organization report of 2015 (WHO, 2015) estimated the death of 1.2 million people worldwide and a more significant number of injuries from road accidents. ERIA (2013) estimated a reduction of accident cases (by 25\%) through the introduction of BRTS.

Hence, BRTS, one such revolutionary approach in the transit system, has been found to have a significant contribution to public life (Jiang et al., 2012). Levinson et al. (2003) made a deliberation of new technologies and features that characterized the BRTS. Abdelghany et al. (2007) proposed a complete BRTS service planning and operations proposal. Tsao et al. (2009) analyzed a single segregated bus lane for BRTS from a feasibility point of view. Bitterman and Hess (2008) described the new system in the context of universal design requirements. A variety of BRTSs can range from grade-separated to at grade busways as reported by Tann and Hinebaugh (2009). BRTS has a strong potential of bringing about a modal shift from a private vehicle. BRTSs are public systems designed to carry a large number of commuters and run on cleaner fuels. Kumara (2009) summarized the present context of the urban scenario, common transportation problems in Indian metropolitan cities, characteristics, and historical development of BRTS. Deng and Nelson (2011) have discussed the increase of its popularity in the global context in their paper. Li et al. (2012) worked on dwell time for transit systems using estimation models. Zou et al. (2012) worked on the performance assessment of BRTS using probe data and signal timing data.

The Transit Capacity and Quality of Service Manual suggest that BRTS can run in three kinds of operating environments - semi-exclusive, exclusive, and grade-separated (Transportation Research Board and National Academies of Sciences, Engineering, and Medicine, 2013). Gandhi et al., (2013) did a detailed analysis and proposed sixteen different design alternatives and evaluated to same. Hidalgo et al. (2013) inquired into the role of facility design infrastructure in improving the transit system's performance. A few more authors elaborated in detail the issues concerning the implementation of BRTS in small and medium-sized towns of developing countries in the Asian Region. Godavarthi et al. (2014) developed a performance model of BRTS using the V/C ratio. Hidalgo and Muñoz (2014) discussed the technological innovations in BRTS so far. Nikitas and Karlsson (2015) did a state of the art SWOT analysis of BRTS worldwide. Kathuria et al. (2016) made a detailed review of BRTS implementation in India. Kathuria et al. (2017) evaluated the performance of Ahmedabad BRTS on aspects related to route design, scheduled planning, cost, service delivery, comfort and safety efficiency.

\section{Need for the study}

India's fast-growing cities are struggling in the transportation sector. Under-capacitated roads, the overload of private and public transportation modes, congested space, deteriorating environment, and the likes characterize traffic conditions in developed countries. As a response to severe congestion, degrading air quality, increasing greenhouse gas (GHG) emissions from the transport sector, rising road accidents, and skyrocketing growth, there is a need to consider the applicability of sustainable transportation system including BRTS in cities across India. Through this, future growth can be organized, and the benefits of resources be meticulously augmented. Amongst the cities in India experiencing BRTS services, only Ahmedabad, Rajkot, and Surat BRTSs are designed as closed BRTS system while the rest are open BRTS (BRTS, online). Open BRTSs are impregnated by multiple problems including infringement, localized crossovers, low maintenance, less control on traffic, and the likes.

This paper aims to discuss various parameters that contribute to the successful implementation of BRTS. It also revolves around identifying the applicability of multiple parameters in developing a BRTS that will function hassle-free.

\section{Challenges faced}

BRTS today in Asian cities, including A hmadabad, Jakarta, Bangkok, and Hanoi, is highly attractive as a mode of conveyance. The high attractiveness is due to the multifaceted advantages of the system. The most successful BRTS operating cities have developed a well-designed city plan integrating land use strategy with public transit and road networks (Satiennam et al., 2006).

Most Asian cities have found to have developed and expanded under a transit-oriented growth model. This model, coupled with weak land-use controls, has resulted 
in urban sprawl, traffic congestion, and deterioration in air quality. All these have further implied a hindrance to the introduction of BRTS in an existing city network (Muhammad et al., 2016).

Delhi introduced BRTS in 2008, but the system failed because of multivariate reasons which include the seasonal influence of smog, the multidimensional effect on other modes of conveyance, low maintenance, increasing affinity of people and the affordability of private vehicles and the likes (Hidalgo and Bhatt, 2015). Using the lessons learned from Delhi's experience, the system should be designed integrating all parameters into consideration.

\section{Bus Rapid Transit}

Many transportation facilities are employed to cater to the needs of a developing city such as walking paratransit etc. but have failed due to heavy congestion and air pollution due to heavy vehicular traffic. Thus, BRTS is used to balance the cost and delivery of an efficient public transport system.

The increasing travel demand of a city is catered by a public transit system such as Mass Rapid Transit System (MRTS) or Bus Rapid Transit System (BRTS). Comparing the transit systems in the context of cost of implementation, MRTS would cost about 200 crores per $\mathrm{km}$, and a BRTS will cost only 20 crores per km (Wright and Hook, 2007). Thus, due to the high cost of MRTS compared to BRTS, they became less financially viable for many cities in India. BRTS in India has improved with high comfort conditions with excellent quality safety features, including dedicated busbay, convenient stations, comfortable articulated buses, and Intelligent Transportation Systems (Wright and Hook, 2007). The element of the right of way (ROW) distinguishes the two types of BRTS, i.e., high-end BRTS and the lower quality system, which is called BRTS Lite [Institute of Urban and Regional Development]. High-end Services, which include an integrated network of routes, corridors enclosed high-quality stations frequent and new rapid services. In comparison, BRTS lite offers some priority but not signal preference, segregated bus bays, and the stations are not modern and have small shelter with fewer passenger facilities and less rapid headway of buses.

In an open system of BRTS, the dedicated lanes are open to all the bus operators. Thus, BRTS has no dedicated corridor compared to closed BRTS, which has a dedicated right of way. Closed BRTSs are most efficient as they are solely responsible for the efficiency of the route. In mixed lane traffic where there is no possibility of using dedicated BRTS lanes, the BRTS service may use the regular lanes with mixed traffic. The implementation of BRTS required half as much time as the implementation of an MRTS thus it has an advantage in cost and time-saving in construction of public infrastructure and corridors of a BRTS.

Further use of $\mathrm{CNG}$ as fuel, increasing ridership, and decreasing personal vehicle on roads reduce Greenhouse gases (GHG), and decreasing local air pollution creates a sustainable environment. BRTS, in some cases, have been found to ferry equal capacity of passengers as metro and can even attain similar speed as they have dedicated movement corridors. This is made possible by reducing headways significantly, resulting in a more significant number of buses to cross a green signal at any given time (Wright and Hook, 2007). Low volume systems are impregnated by problems of bottlenecks that appear at cross-over points. Hence signalized intersection is a priority in such bus bays.

In developing countries like India as also in other Asian countries, the bottlenecks appear at bus-stations. Hence for giving priority to BRTS buses, the traffic lights always need to be green so that bus headways can become a priority. Thus, the BRTS constitutes of most functions that prioritize to reduce the dwell time of buses at the bus station.

\section{Impacts of BRTS}

Socio-physical context is a tangible aspect where social activities assume a platform to exhibit themselves. A highly regarded socio-physical setting is generally usercentric in its design and intended to increase satisfaction. For BRTS, the transportation features and designed physical environment are the key factors in identifying user satisfaction.

Research carried out by Swamy (2014) on Jamnagar BRTS shows that until 2014, the rate of new commercial buildings in Shivranjani area (with BRTS) has increased significantly by $292 \%$ while increasing by only $123 \%$ in Shyamal Cross Road area [Ahmedabad Municipal Transport Service (AMTS) only]. As indicated in the study, along the BRTS corridors, land prices rose by $50-105 \%$ for residential and 60-185\% for commercial building (after Janmarg began operating) (Swamy, 2014).

Extensive research proposes that urban quality of life has been enhanced by introducing BRTS, the most notable instance of which was observed in systems like Bogotá's TransMilenio. By excluding BRTS buses out of the main traffic flow, passenger travel time reduces significantly. Parallelly, due to designed advanced signaling system and bus frequency, transit time and waiting time for single passenger has diminished with the implementation of BRTS. 
The BRTS has established to have a positive effect on property value leading to appropriation of profits. This typically takes the form of higher property values and benefits of transportation infrastructure surfaces as land-values leading to land-use intensification (Cervero and Kang, 2011). Sharul (2014) discussed the impact of KL-Klang BRTS, where analysis suggests that the BRTS anticipated saving fuel cost by RM 4.8 billion per year up to 2020 and RM 6.1 billion up to 2030. Lesser fuel consumption will lead to lower pollution resulting in pollution saving of RM 160 million per year in 2020 and RM 200 million in 2030. Lower congestion will add (RM 160 million) to the exchequer RM 520 million per year in 2020 and RM 862 million per year in 2030 (Sharul, 2014). The replacement of old transport facilities with BRTS in many areas has reduced GHG emissions, leading to cleaner greener environments.

\section{Comparative methodology}

With the help of examples of many cities that have successfully implemented BRTS services, the methodology to be adopted will involve studying different cities' processes, including the strategies used for providing efficient transit system or bus rapid transit system. Thus, by comparing various strategies used by different countries to implement BRTS corridors and to extract the best possible approach to implement BRTS in Indian cities.

\subsection{BRTS corridor}

\subsubsection{Corridor selection}

Corridor selection is an essential part of implementing a BRTS as the present and future impacts depend on it. The corridor's choice depends on various factors such as Right of Way, ridership, road character inventory, existing and future land use, growth directions, present, and future population. The estimation of employment needs to evaluate the ridership of the BRTS, considering the existing road conditions. The main objective is to reduce overall travel time to the stations for the population; as a result, the corridors are mostly located along with significant places or landmarks such as schools, colleges, malls, markets, or institutional areas.

The areas with high ridership, their activities, abutting land use, road and lane capacity, fragile V/C Ratio, and available ROW usually selected as thrust areas for implementation. Access to middle-income groups, mixeduse, and commercial areas may be a deciding factor for choosing any corridor. Bogota TransMilenio targeted the low-income group in the south in deciding the first phase of the BRTS corridors. The trail corridor was designed to pass through the CBD housing the employment zone of the city. The roads in these areas have limited space, and a high concentration of employment thus would require direct access to other areas. The system survives if the demands of people's mobility are met by the selection of corridors (ITDP, 2017).

\subsubsection{Roadways}

There are two types of systems depending upon the ROW of roads and the Trunk and Feeder system-arterial thoroughfares majorly used for trunk BRTS corridors. Due to the population density being very high along the arterial roads, they can also accommodate both dedicated busways and mixed traffic. All the significant connections are covered by the arterial roads; thus, an integrated network was established. Due to the broader ROW, the construction cost of the corridor is less. The noise level problem usually occurs, is also much less as their roads have accustomed to the high presence of motorized traffic.

Secondary roads are also considered for the trunk system. The streets that run parallel to the major arterial roads considered because the traffic condition on the arterial road may not allow safe boarding to the commuters or absence of proper crossings at major intersections that may hamper the easy boarding of the passengers in the system. The secondary roads are also calm traffic areas; thus, they are very suitable to be converted into BRTS only roads, but the feasibility of this may depend on the road's existing usage.

\subsection{System capacity}

\subsubsection{Capacity of the vehicle}

The capacity of the bus is directly related to the length of the bus with 3 meters for the engine and driver and 1 meter for every ten persons for a balance (Wright and Hook, 2007). TransMilenio Bogota has set a good standard for BRTS buses, which has been adopted by various other BRTS systems because efforts in other BRTS to introduce longer buses are expensive.

\subsubsection{Load factor}

An alternative way to augment system capacity is to increase the passenger capacity of the bus. It involves re-routing bus lines already in service in a corridor. One of the systems used in BRTS is the Open Route System, where a BRTS bus carriageway is only segregated from the spine by application of divider. This system is advantageous over a closed system as there is no change in the bus-bays. 
The actual capacity of a mode of transport upon its carrying capacity is termed as Vehicle Load. It is expressed in percentage. Hence if a bus has a carrying capacity of 120 passengers and on an average carries 90, its Vehicle load is $75 \%$. As a standard practice, it is not advisable to run a system at $100 \%$ as it leaves no room for delays and irregularities, which may arise due to increasing congestion on the roads. The required load factor may vary between peak and non-peak hours. In TransMilenio Bogota, the peak load is $80 \%$, and that of the non-peak hours is $70 \%$ (Wright and Hook, 2007).

However, the buses in an open BRTS do not run with full capacity. If the passengers' total volume is below 70 per hour, there arise no problems, but above 70 per hour, the busways start to congest. To address the issue, buses in the lanes are reduced to maintain bus speeds. The easiest way to deal with the problem is to shift from the direct route to the trunk and feeder system (Wright and Hook, 2007). This system will automatically increase the load factor of the buses.

The BRTS in the US, Sao Palo, Brisbane, Kunming, and the HCBS in Delhi are open BRTS (ITDP, 2017). Before TransMilenio Bogota had been built, a regular bus system was in use, which had two lanes per direction. It carried 30,000 passengers per hour in each direction. But the speed of the buses was only $12 \mathrm{~km} / \mathrm{h}$. The Passarapido system in Sao Palo moves the passengers at $12 \mathrm{~km} / \mathrm{h}$. due to heavy congestion on the roads. The system constructed in Delhi is also an open BRTS which runs 200 buses per direction per hour. Two full boarding platforms have been erected, but the BRTS design consumed a lot of ROW (Wright and Hook, 2007).

TransMilenio Bogota introduced a BRTS and named it as Closed Trunk (ITDP, 2017). It was designed for high-capacity and high-speed with a feeder BRTS but adopted a low-cost system. It shifted from a direct routing system to a trunk and feeder system. It privileged ferrying of the same number of passengers through the same corridor consuming less space. It also deployed fewer buses contrary to increasing the size of the bus.

\subsubsection{Feeder system}

Can a BRTS service run without a feeder system? Many cities have implemented BRTS without the feeder network or direct services into the residential areas. This type of arrangement usually occurs when a city tests the BRTS network in the first phase. In this way, the municipality can avoid any complications with the existing transit providers in the residential areas.
Jakarta Indonesia started its first phase of Transjakarta BRTS of $12.1 \mathrm{~km}$ in January 2004 (BRTS, online). The system consisted of a single median line bus bay system. The corridor passes through the high commercial district and some residential linkages. The municipal corporation decided not to open a feeder line and only operate the single median trunk line.

They also allowed the existing bus service to run in the mixed traffic. The results thus obtained were not as successful as expected. The BRTS could carry only 60,000 passengers per day with a peak hour capacity of 6,000 in each direction. The lack of feeder resulted in heavy traffic congestion (Wright and Hook, 2007).

The Jakarta experience first resulted in the impression that Transjakarta BRTS has insufficient demand for being a BRTS, and the design increased the congestion level. The negative impact on the people through the press and media has given the Transjakarta BRTS a severe standpoint in public relations and made it challenging to implement in other corridors. With the existing bus service present, it increased the congestion level, which was the target area of the BRTS. Thus, with the lack of a feeder system, it becomes challenging to operate a new BRTS.

\subsubsection{Bus frequency and headways}

Planning of bus headways is important in the inference of bus frequency. For cities with excessive population, bus frequency has increased, and capacity has doubled or tripled by increasing the number of buses per hour without congestion at the station. Dwell time depends on the number of passengers embarking and disembarking at a bus station and the time required to complete the activity. This also includes the amount of time needed for a vehicle to stop, open doors and close the doors after the passengers' boarding. All these aspects have been used to determine the actual dwell time at stations. A standard bus station is capacitated to handle 3000 passengers per hour in each direction. This number is valid if the passengers don't purchase tickets at the station but on a bus (happens typically in standard bus systems in Indian cities). The capacity can be increased by 4000 pphpd through design interventions. If the passenger does not have to climb up to board the bus through a staircase and directly board the bus from the bus platform, it increases to $5000 \mathrm{pphpd}$. If the passengers pay before boarding the bus through four large doors simultaneously boarding and get off the vehicle through two doors of 1.1 meters the capacity increases to $9400 \mathrm{pphpd}$ (Wright and Hook, 2007). 
TransMilenio buses have four doors, two of which are used to for boarding and two for leaving the vehicle. This increases the capacity of the station to handle more passengers per direction per hour. For a BRTS to process 9400 pphpd, buses are required to enter and exit stations in triplets or more, which is technically termed convoys. With this technique, the station capacity can further increase to 16000 pphpd. In the case of over-burdening at bus stations and to avoid congestion, separate overtaking lanes may be incorporated (BRTS, online).

With two bus platforms per lane the headway can be reduced to 30 seconds, and the overall capacity can increase to $18000 \mathrm{pphpd}$, and with three bus platforms, the headway can be reduced to 16 seconds, and capacity can increase to 36000 pphpd. TransMilenio forbids left turn at all major intersections. This reduces traffic delay giving almost half of the signal green phases to the BRTS (BRTS, online).

\subsection{Dwell time}

Another factor affecting the service operations of a BRTS is the Dwell time - the time a bus halts at the station to facilitate passenger boarding and disembarking off the bus. In general, the boarding time for a BRTS service can be as low as 20 seconds. The dwell time usually depends on the system load, which is higher at peak hours and more economical at non-peak hours.

Another performance factor to the dwell time is the Saturation time at a given stop. It measures the congestion at a given stop, using Eq. (1) by (Wright and Hook, 2007).

Saturation Level at a stop $=$

Dwell Time (Mins) $\times$ Frequency of buses (buses per hour)

For example, the dwell time of a bus in BRTS is $20 \mathrm{sec}-$ ond, and 60 buses are plying per hour, then the saturation time will be:

Saturation time $=\frac{(20 \text { seconds } / \text { Bus }) \times(60 \text { Buses } / \text { hour })}{(3600 \text { seconds } / \text { hour })}=0.33$

As the value approaches 1 , the chance of queue of buses increases.

\subsubsection{Passenger capacity}

The capacity of passengers for a given corridor thus can be calculated by vehicle capacity, dwell time, load factor service frequency, and the number of stops. A different combination of the factors related to passanger capacity is given in Table 1. All these are considered for calculating the passenger capacity using the software. The equation (Eq. (3)) involved is:

Passenger Capacity $=$

Vehicle Capacity $\times$ Load Factor $\times$

Service Frequency $\times$ No. of Stopping Bays

Table 1 presents different combinations of the above factors for the following:

- Vehicle capacities -

- Standard Bus: 12M 70 passengers

- Articulated Bus: 18M 120 passengers

- Bi-Articulated Bus: 24M 270 passengers

\subsubsection{Local services and station locations}

BRTSs are characterized by local services, which means stopping at each origin and destination point. Compared with the conventional bus system, the BRTS stops are spaced at a greater distance then standard city bus stops, usually 300 to 500 meters apart. By avoiding short distance stoppage, overall travel time reduces compared with the hail and board system of a standard bus system in which the vehicle stops whenever the passenger indicates to board or get off the bus. With this control from passengers, the stoppage of the bus increases the overall travel time.

Identifying a BRTS station location not only depends on origin and destination but also catchment areas. The stations are placed according to the major destinations such as commercial centers, educational institutions, Public institutions, main markets, etc.

Table 1 Different combination of factors related to passenger capacity. Source: (Wright and Hook, 2007) Bus Rapid Transit Planning Guide ITDP

\begin{tabular}{lcccc}
\hline $\begin{array}{l}\text { Vehicle } \\
\text { Capacity }\end{array}$ & $\begin{array}{c}\text { Load } \\
\text { factor }\end{array}$ & $\begin{array}{c}\text { Headway } \\
(\text { Sec })\end{array}$ & $\begin{array}{c}\text { No. of } \\
\text { Stopping Bays }\end{array}$ & $\begin{array}{c}\text { Capacity } \\
\text { flow }\end{array}$ \\
\hline 0 & 0.80 & 90 & 1 & 5040 \\
160 & 0.80 & 90 & 1 & 11520 \\
270 & 0.80 & 90 & 1 & 19440 \\
70 & 0.80 & 90 & 2 & 10080 \\
160 & 0.80 & 90 & 2 & 23040 \\
270 & 0.80 & 90 & 2 & 38880 \\
70 & 0.80 & 90 & 4 & 20160 \\
160 & 0.80 & 90 & 4 & 46592 \\
270 & 0.80 & 90 & 4 & 77760 \\
160 & 0.80 & 90 & 5 & 57600 \\
270 & 0.80 & 90 & 5 & 97200 \\
\hline
\end{tabular}




\subsubsection{Limited Stop Service}

Not all stations are essential. Some stations dominate the travel demand of passengers and a frequent stop thus increase overall travel time and provides less commercial value to the system's operator. Therefore, it is more beneficial for the passenger and the operator to skip intermediate stations and provide a limited stopping service with less travel time. The ridership decides the numbers of stations that are avoided at stops. The stops with high ridership and demand can be the most logical ones. There can be different limited-stop service depending upon the travel time reduction, i.e., depending upon the number of stops, a limited-service may skip 2-3 stations, or different service may skip station double the previous facility. Thus, depending upon the number of stations to be skipped, other limited stoppage services can be created.

Interchange can be created at some stations depending upon the ridership and travel demand. Commuters can change from a limited stopping service to a local service to reach their destination. This user-centric design will enable passengers to have flexibility in reaching their destination at the required time. While the limited-stop service provides greater flexibility to the commuters it is relatively hard to manage in a corridor with different travel characteristics.

This requires vehicle tracking ITS systems controlled by the control center that monitors the movement of buses in the corridor. A limited stopping service also requires infrastructure additions such as passing lanes at intermediate stations so that the service could easily pass through an intermediate station. Thus, a city with a limited-stop service will have high infrastructure costs and greater system complexity than a local service.

\subsubsection{Express service}

Express service is a kind of limited stopping service. The express service will not stop at any station between the peripheral area and the central core area. The reduced travel time can be a significant point of attraction for the commuters as the lower and middle-income group people live in the peripheral regions of the city. This service would be beneficial for them and could control private vehicles' growth in the city's outer areas.

\subsection{System management and control}

\subsubsection{Centralized control}

Centralized control of the transit system has many advantages, such as increasing efficiency and reducing cost. The standard bus system usually lacks a centralized control and management system. Due to uncontrolled buses, each service performs independently without any restriction to respond to changes in the service. For example, high demand in an area can be adequately dealt with by centralized control. In case of a breakdown, if a repair team's on-time response is weak, it could hamper the operations and create a jammed situation. These problems lessen using centralized control.

Centralized control is also necessary when handling a large volume of passengers to maintain uniform and smooth operations. This reduces the chances of a bunching of services at a location. In this situation, 2-3 buses will arrive at the same station simultaneously, which will increase the wait time, and there will be no bus for some time - these result in low customer satisfaction and a decrease in ridership of the system.

The system monitors and evaluates the bus system. As the system records, all movement of the bus services revenue can be distributed and accounted accurately. It also monitors driver behavior and problems related to the staff of the various services.

\subsubsection{Operational control}

In the case of a high travel demand corridor, if a bus breaks down, it can create disturbance in the corridor by creating a jammed situation, thus stopping all the services in the corridor. In case of a ticketing system failure or a door mechanism, failure similar circumstances may occur. Therefore, preparing for situations like this is the primary aspect of an operation plan. The preparation of a backup plan for these situations is required to guarantee the system's smooth functioning.

\subsubsection{System map}

In many countries, the transit ways are arranged in an informal and uncontrolled way, which requires some experience to understand the system entirely. Many of these systems have formed a barrier towards its potential consumers in terms of difficulty interpreting the system. The system of TransMilenio Bogota has become an example in the world for its BRTS service by providing a bright and colorful map that is easy to understand. This enables passengers from different places with different languages to understand the system within minutes by seeing the map.

\subsection{Infrastructure}

\subsubsection{Right of way}

Right of ways is an essential factor in designing and planning of busways for the BRTS. Provision of BRTS lanes, 
Pedestrian facilities, cycle tracks, and mixed traffic lane becomes a challenging task due to existing constraints in the Right of Way. A wide variety of designs of carriageways have been implemented in many cities considering a Right of Way of 22, 24, 30, 32, 40, 45, 60 meters, respectively (BRTS, online). BRTS buses are usually $2.6 \mathrm{~m}$ wide, and for easy maneuverability, the BRTS lane provided is of $3.5 \mathrm{~m}$ width. The median stations usually $4 \mathrm{~m}$ wide with two BRTS lanes on either side, making the whole cross-section of $11 \mathrm{~m}$. The size of the BRTS station may depend upon the ridership and demand of the area thus; they can have single or dual bus bays.

\subsubsection{Lane system}

The selection of the bus lane is an essential aspect of BRTS. The most commonly used type in India and other developing countries is the median busways system. This system reduces right turn conflicts at intersections and allows serving both BRTS lanes of either direction. The median busway system also reduces the cost of construction, which may occur in a curbside busways system. Similar instances are seen in Janmarg BRTS in Ahmadabad, Rainbow BRTS Pune, and Indore BRTS etc. (BRTS, online).

They also provide easy integration with other bus systems across the intersections. In the case of median bus bay system, the system can be of two types namely Flow System, in which the bus system may run along the direction of the mixed traffic and Counterflow system in which the bus system can run in counter-clockwise to the course of the mixed traffic. Instances used in India usually follow Flow system.

Counterflow systems have a main disadvantage of safety as pedestrians do not look in the opposite direction to the mixed traffic to cross the bus lane; thus many accidents tend to happen. In some instances, the busways cover the entire road, and there is no mixed traffic intersecting with the BRTS lanes. The BRTS implemented in Pittsburg USA has streets (exclusive) for BRTS (BRTS, online). Another system used is the Curb Side Bus Bay System. Many BRTS do not widely use this system as the main disadvantage of the system is the conflict with the traffic at intersections. With these conflicts, the speed and uniformity of the BRTS hamper. The integration with other bus system is also difficult with this type of bus bay system as the commuter must cross the road to reach a different direction or bus system.

\subsubsection{Overtaking lanes}

Bus bay system with single BRTS lanes has limited capacity, which can be increased with multiple stopping bays at a station, but this system is challenging to manage. Thus, the best way to overcome the capacity restrain is to construct overtaking lanes at bus stations or an additional lane throughout the corridor. Construction of additional lane may not be possible in a corridor with different Right of Way (ROW) in a smaller ROW. The additional lane will create bottleneck situations by decreasing the overall width of the lanes for mixed traffic. Overtaking lanes at some corridor stations with a lesser demand and lower ridership is possible with higher ROW to avoid bottleneck situations. The limited stopping service or the express services are accommodated in the additional lane, constructed in this way. The main disadvantage of overtaking lanes is the effect on overall road space. Many cities in India have less or non-uniform ROW and may not be able to provide overtaking lanes for the BRTS. Overtaking lanes have been proposed in the Janmarg BRTS in Ahmadabad at four different locations, in the city of Barranquilla Colombia addition road space is acquired by purchasing property abutting to the corridor for construction of overtaking lanes in some areas (ITDP, 2017). The acquisition of properties for road development depends upon the local laws and property rates and the benefits given to the owner of the plots.

\subsubsection{Grade separation}

The reduction in travel time for BRTS is contributed by independent busbays, well-designed BRTS stations, and rapid changeover facilities. Intersections and interference with other vehicles with the BRTS cause delays increase the overall travel time and decrease the system performance. Thus, segregation of bus bays from other mixed traffic areas such as intersections and other points of conflict is advantageous for reducing travel time and increasing safety. Therefore, there are two types of systems at grade system and grade-separated system.

In an at-grade system, the lane runs along with the standard grade with the mixed traffic and must deal with signalized intersections. This contributes to the reduction of speed, thereby increasing the travel time. In a grade-separated system, the conflicts with mixed traffic are substantially avoided by the construction of grade separators such as underpass, overpass, and tunnels. With the design of grade separators, the cost advantage is reduced due to the increased construction cost. In the city of Quito, they have 
extensively used underpasses to avoid delay due to signalized intersections. According to Quito, the significant travel time was saved, and increased ridership would justify the increased construction cost of the subways.

\subsubsection{Lane maintenance}

The BRTS runs with buses, which always subjected to wear and tear and hence can experience breakdowns on the way. Since BRTS has a single dedicated lane in most cases, a little disruption can cause severe complications and inconvenience to passengers. The fact of Pune Rainbow BRTS bus breakdown in August 2018 is a living example. Hence, it needs to be accessible to Tow car at Bus station points and bus turnouts designed within the BRTS corridor for necessary maintenance work.

\subsection{Bus stations}

\subsubsection{Location}

The location of BRTS stations is an essential part of the system. The location and design of BRTS station will affect system flow capacities and passenger amenities such as safety and security. The BRTS station location depends upon demand in areas such as shopping complexes, CBD's, Stadiums, recreational zones, malls, etc. The distance between each station is the sum of demand at different locations. The standard distance between each station is usually $500 \mathrm{~m}$, but it can range from 300 to $1000 \mathrm{~m}$ depending on the local transit demand (Wright and Hook, 2007).

\subsubsection{Station size}

The entry area, pedestrian refuge, ticketing area, and the waiting area are designed considering passenger flow and transit demand of the area served. A BRTS station is to be developed in such a way so that it can handle future passenger growth and demand. The station area is to be such that it can accommodate the number of commuters without any discomfort. The size of a station depends on the available space on the road. The usual width of the BRTS station is between $3 \mathrm{~m}$ and $5 \mathrm{~m}$. The overall area of the BRTS station can be increased by increasing the BRTS station (ITDP, 2017).

The length of the BRTS station depends on the number of buses stopping at a station and the number of bus bays provided. If a station uses multiple bus bays or various BRTS services, then the bus station length may be higher. The distance between the stopping bays depends upon the required turning distance for the bus to park or disembark from a bus bay. Different stations will have different sizes for a station serving multiple routes will have a higher number of stopping bays that will have a greater length. If a station is serving a few routes, it may have a single bus bay, and the length of the station may be smaller. Similar instances have been used in Janmarg BRTS Ahmadabad single bus bay stations at Chandala Lake bus station. Multiple bays are used at several locations, such as Memnagar, Maninagar, etc. (Gautam et al., 2014).

\subsubsection{Access to stations}

Ease of access to the station plays an important part in the BRTS and would help in responding to passenger demand. The provision of pedestrian cross-over points can further promote safe and comfortable access to the station. Street lighting, pedestrian signals, appropriate system signage, and proper sidewalks will help customers use the BRTS. Access to the entry of the BRTS station is an essential factor in reducing travel time. If there is crowding at the station entrance, the overall travel time increases. With spacious entry and exit areas of the station, the problem of chaotic boarding and alighting points can be resolved.

In Curitiba BRTS, the rear entrance is used for boarding, and the other door is used for alighting. This arrangement helps in reducing the overall dwell time of the passenger at stations. In this kind of agreement, a passenger should know to disembark the bus at the specific gate.

\subsubsection{Interchange stations}

A BRTS includes many corridors allowing interchange between them. It requires a mechanism so that a passenger could cross from one corridor to another to reach the destination. Thus interchange stations are used. An interchange station is built between two trunk lines (between two lanes of different corridors) (ITDP, 2017). The infrastructure may be single bay or dual-bay, the multi-level station where each corridor is placed on an individual level or one above the other. The main disadvantage of the system is the increased cost of construction. The system mainly facilitates less walking distance between two corridors.

Indian cities can create underpasses or overpasses from the station of the respective corridor to another to enhance connectivity. The access to the pedestrian underpass/ overpass restricts only BRTS passengers. This system is cheaper in construction than prevalent systems like multilevel change. Further, such systems are disadvantageous to passengers as they must commute long distances.

The same instances are in Janmarg BRTS Ahmadabad in Jhansi Ki Rani Station, which acts as in interchange 
between BRTS and Gujarat State Road Transport Corporation (GSRTC) buses with at grade pedestrian access. The Anjali Station serves as an interchange between two BRTS routes. The Geeta Mandir Station provided crossing to GSRTC terminal with a pedestrian at grade access between 2 BRTS corridors passing at this junction (Gautam et al., 2014).

\subsection{Feeder transfer stations}

Feeder lines do not necessarily intersect at the intersection but can also intersect at different points in the corridor known as feeder transfer stations. These stations are somewhat a mixture of both BRTS and local stations. Unlike terminal interchange stations, they do not have platforms for both services. Ideally, the feeder services can enter the segregated bus bays to avoid concerns related to a single fare system for both feeder and trunk lines (ITDP, 2017). Usually, the feeder service is operated on smaller streets; thus, the passengers from the feeder system have to walk to the trunk stations to reach their destination. To connect stations (Feeder interchange and Trunk station) overbridge, underpass or pedestrian walkways prove useful.

\subsection{Terminals}

Terminals may have the same design as the system stations; as the terminals cater to many passengers, they require more space. The terminals are designed either with a complete enclosure or with no walls around the entrance. The terminal designs in the cites of Quito and Bogota have high ceiling designs (ITDP, 2017). The number of terminals in a corridor depends on the number of feeder lines intersecting at the terminals site. Usually, terminals are provided at the ends of the corridor.

Terminals can be placed in the center of the corridors if many no. of different BRTS corridors pass from the center. Usually, terminals are designed with feeder interchange so that passengers could quickly transfer between the unusual trunk and feeder services. The free transfer system supports the transfer between the various functions. In case of different fare system at terminals for different services enough space is to be provided for fare collection and verification processes.

The space provided for terminals can also be used for commercial activities such as food provision and average shops, general stores, telephone booths, kiosks, etc. These activities should be allotted space outside the terminal building and placed in the terminal area to decrease maintenance issues and premature aging of the infrastructure.
Similar instances of the terminal with interchange are proposed in Janmarg BRTS in Ahmadabad, where the Janmarg BRTS, GSRTC, and other feeder services would converge (Gautam et al., 2014).

\subsection{Depots}

Depots play an essential part in the BRTS as they comprise parking, refueling, maintenance areas, administration offices, operator offices, etc. The depots' location is planned close to the corridor as the operator may want to include a higher number of buses to cater to the increased demand in the corridor. As the buses leave the depots without any passengers and travel to the respective corridors, dead kilometers occur between the depot and the corridor. Thus the location of depots is to be planned to decrease dead kilometers as much as possible and to reduce operating costs. As depots require ample space, the location depends upon the availability of land near the corridors or on the rules for the acquisition of land prevailing in the city.

The depots should facilitate the fast movement of buses without any obstacles. The internal depot movement should be in response to the system. First, the vehicle will move towards the refueling area where the overall mileage and fuel level will be checked, and then they will move towards the parking bay to be used when the demand increases. After that, they may move towards the washing area and finally towards the maintenance area/repair area. Similar strategies of depots planning near the corridor are in Janmarg BRTS Ahmadabad, where the depots for phase I are prepared near Chandola Lake, and the second is proposed in Odhav (Gautam et al, 2014).

\subsection{Feeder infrastructure 8.10.1 Feeder lanes}

Feeder lanes are generally not provided with a segregated bus bay as they run in narrow residential areas, and they usually run in mixed traffic lanes. There may be instances depending upon the available ROW to provide segregated bus bays for feeder system with Queue Jumping Mechanism. The mechanism applies at signalized intersections. Bus service may enter the lane in order to gain priority over other mixed traffic in the lane. A separate signal system for feeder buses at lanes may also help reduce overall travel time for the feeder passengers.

Overtaking lanes are also helpful to reduce travel time for feeder system which further depends on the available Right of Way (ROW) at the respective streets on which they run. This may help the feeder services avoid areas prone 
to congestion and reduce travel time. Similar instances have been used in London where small overtaking lanes are employed for its conventional bus services. This has helped the London bus system avoid the bus schedule's unpredictability due to congestion on streets (Wright and Hook, 2007).

As the trunk system used the median busway system the feeder system uses the curbside of the street and cannot be segregated from the mixed traffic; thus, they are vulnerable to be infringed by mixed traffic on the bus-only lanes. The Feeder lanes intersect with the mixed traffic at intersections to make right turns, thus increasing the overall travel time. To deal with vehicles encroaching the bus-only lanes in feeder system London has employed CCTV cameras at intersections and at lanes to record the registration number of the vehicle infringing the bus lanes of the feeder.

\subsubsection{Feeder stations}

In the trunk system, which benefits from the well-spaced stations same should be employed in feeder system stations. The spacing of the stations in feeder system is to be placed a little closer than the trunk system to justify the pedestrian conditions in cases where the latter is underdeveloped or in poor condition. The spacing of the station may depend on factors such as major intersection, activities, malls, etc. depending on the local circumstances.

Feeder system stations are not architecturally sophisticated as their counterparts in the trunk system, but they should also provide safe and secure boarding and alighting from the services. The feeder station in comparison to the trunk station needs not to be closed and have bus bays. In many instances, the maintenance and funding of the feeder stations are done by advertisement panels. Still, care should be taken that the panels do not block or decrease the accessibility and safety of the passengers.

\subsubsection{Multi-modal integration}

Public transit is incomplete without different modes of transportation. The initial trip starting from the origin may involve walking, two-wheelers, private cars, bicycles, Auto-rickshaws, etc. Once the passenger exits a station the other form of transit options will complete the ultimate journey to the destination. Integration with these types of transit options is essential for running a viable public transit system. The environment around the public transit, which supports other forms of transportation to integrate and allow passengers a safe and secure way to utilize public transit, is an essential factor that attracts passengers to use public transit instead of private vehicles.

\subsection{Communications}

\subsubsection{Public participation processes}

The main deterrent in implementing a good BRTS in developing countries like India is neither technical nor financial but is mostly political since neither communication nor people's participation remains primarily wanted. Public participation is significant as it is necessary to communicate to the people for their approval and to learn about their demands. Thus, by incorporating the requirements and design alterations required by the public, the public transit system can be benefitted as the people and users would fully accept it. Non-Governmental Organizations (NGOs) may be useful in managing the public participation process, which may or may not be done by a Government organization.

\subsubsection{Existing transportation network}

Changing an existing system and introducing a new is a challenging task. In many countries, the current transit operators are not willing to allow any government agencies to interfere and oversee their operations. It is very likely that the existing transit operators carry distrust with any public agencies; many cities in India have sparked violence and vandalism against any new implementation of the public transit system. In the case of Ahmadabad, the BRTS is integrated with the existing Ahmedabad Municipal Transport System (AMTC) services to provide a feeder connection to its corridors. Also, the IPT system has been integrated to transit commuters to their destinations from the BRTS corridors. The existing operators can come into a plan with BRTS as an excellent business opportunity and should not consider the system as a threat to their future. This depends on how the municipal corporation of an area introduces the BRTS and discusses the future with the existing transit operators (Gautam et al., 2014).

It is essential to integrate existing public transit personals in the organizational structure of the BRTS. Visits to cities with existing BRTS may solve the problem during which the current operators can assess the BRTS by communicating with the existing operators involved with new systems in cities such as Ahmadabad, Indore, Jaipur, etc.

\subsubsection{Marketing plan}

BRTS services are different from any other Bus system, and marketing this service to the public is tedious with the presence of existing Bus services. Thus, the right marketing campaign is required. Public transit is considered unclean and particularly comfortable. Therefore, a good 
marketing strategy is needed to promote the new transit system in the city and make commuters use the new system. The case of TransMilenio in Bogota deserves mention as few unrelated enterprises co-opted the name into their business model (Wright and Hook, 2007).

Copying the name of a system to profit another bus system should be avoided as it may degrade the overall image of the new transit system (BRTS). The same cases were reported in Bogota TransMilenio where other bus services started to copy the name and degraded the system's image.

An efficient market plan begins after identifying the future user group of the service by understanding the city's needs in public transit. A standard marketing plan can be developed for the Bus rapid transit.

\subsubsection{System logo}

The name and logo are other vital factors in developing an image of the BRTS as a new transit system in the commuter's mind. A strategic marketing plan is thus required to set a picture of the BRTS in the commuter's perception. The cities that have implemented a successful BRTS have set different marketing identifications of the system to look different from the existing bus system. As an example, the name of TransMilenio was chosen for Bogota, Columbia, to represent an image (ITDP, 2017).

The proposed BRTS of Bogota has accepted the name of TransMilenio with the aim that the system will revive the image of the city through modernist and sophisticated approach. To promote the system, the red colour was chosen along with the logo to symbolize it as the life-blood of the city. Similarly, the proposed BRTS in Guayaquil (Ecuador) was named "Metrovía", and the BRTS system in Ahmadabad was called "Janmarg" depicting the central spine of public welfare in mass transit. The BRTS logo should also be integrated into the buildings and station so that people recognize the system. It should be placed in the corridor signage boards so that the commuters know the stations are in proximity and help them board and reach their boarding station easily. The logos should be integrated into the corridors so that passengers recognize the BRTS corridor.

\subsubsection{Public education}

The BRTS is designed to provide a range of services and facilities to the public; thus, a proper public education campaign is required to educate people about the merits of Bus Rapid Transit compared to other transit services. The campaign for promoting BRTS is more educational as the entire focus is to raise awareness of the users. The strategy adopted for the same is more of a marketing strategy. Many BRTS across the world, including TransJakarta, TransMilenio, and Guangzhou BRTS, Janmargh have adopted brand logos and unique system livery for stakeholder outreach (BRTS, online).

The educational campaign starts way before the actual implementation only when the system is conceived and proposed. For instance, information kiosks and public outreach workers are employed by many cities to educate the people about the system. The information kiosks are generally planned inside public areas to use the kiosks as information centers. A similar instance can be found in the new train system in Kualalumpur, where the information kiosks were planned in all the malls and at metro stations to educate and spread awareness about the new trains. Similar public outreach programs were used in Bogota TransMilenio and Ahmadabad Janmarg to spread awareness about the new system (ITDP, 2017). This also helps the commuters to get an idea of how the system will work and function. The city of Lima in Peru adopted an innovative technique to educate people about BRTS by developing a model bus station with a vehicle in the Central park of the city (ITDP, 2017). Such small-scale demonstration provided to be extremely useful as people interacted to gather knowledge about the new concepts of BRTS. Such a demonstration did not offer any service but helped the people by providing them a tangible experience of the proposed system. The residents were provided with an opportunity to practice the adopted fare collection system, which diffused future uncertainty to the ridership (Wright and Hook, 2007).With the help of public demonstration, excitement can be created in the minds of the people so that they can see the new system shaping the new public transit it merits and the advantages for people using it.

\subsection{Accident, safety and emergency management}

BRTS across the world experience accidents. While the running of BRTS buses in identified lanes often makes the management of post-disaster scenario cumbersome, the reasons for accidents are multifarious. Counterflow mechanisms in buses of Mexico and Porto Alegre had a considerable contribution to high accident rates (Duduta et al., 2012). Rainbow BRTS of Pune is highly intercepted by smaller vehicles infringing into the BRTS corridor, causing accidents. Numerous additional reasons contribute to accidents along BRTS, and they include driver's performance, improper fencing, inadequate signalized 
intersection, weather and climate, design of pedestrian corridor and stations, and the likes. There is a need to have adequate emergency response and timely assistance for the injured. The highly-rated BRTS of Bogotá, Guangzhou, and Lima, Peru, have focused and upgraded themselves to improve speed, dependency; service quality through the introduction of GPS monitored bus locations, and overtaking lanes at bus stations (Cervero, 2013). The entire layout was remodeled to make it friendly for the movement of BRTS without interruption and enabling a safe environment for travel. The concept of retention pockets may accommodate Tow-car and ambulances in accident hot-spot zones to respond to the crisis when required immediately.

Road safety audit of Pilot BRTS Pune (TSEG, 2014) identifies that for Pune, transverse rumble strips lie close to signal, unwanted opening in barricading enabling trespassing, absence of bus-lane signage and road marking, undulations in surface leveling, absence of BRTS segregation in many areas contributes highly to accidents in BRTS. So, to curb the accidents, it was prescribed to improve road signage, control bus speed, discourage overtaking in lanes except at stations, close all unwanted infiltration points, mitigate bus-to-platform gaps, and improve pedestrian facilities. The interventions resulted in curbing of accidents.

\subsection{Institutional arrangement and delivery}

Institutions have an immense contribution towards the successful execution and operation of BRTS. Most of the BRTS in the developing world are managed by public authorities or companies focusing on public service. Thus, in many cases, the level of services is compromised. In TransMilenio, Bogota, Medellin, Colombia, GBRTS, Guangzhou, etc., BRTS is managed by separate BRTS authorities while in Johannesburg, Rio-de-Janeiro, Cape Town, etc. it is managed by Transport Department BRTS. In higher-income countries like Rouen, Paris, Amsterdam, etc. it is being led by Contracted Transit Service Provider (ITDP, 2017). In Janmarg, the service is provided by AMTS. TransMilenio's early years as BRTS was a success story of exceptional management focused on maintaining and upgrading the level of services (ITDP, 2017). The later phase saw disputes and unresolved problems in operation. In India, under Jawaharlal Nehru National Urban Renewal Mission (JNNURM), the creation of a Special Purpose Vehicle (SPV) was made mandatory for receiving central grants for BRTS construction. Delhi BRTS also created SPV to manage the dedicated corridor, but there was confusion in the regulation of vehicle operation coupled with poor services, design flaws, and jumping of signals. In Rajkot BRTS, the authority has made it mandatory to have buses that run on CNG fuel, with modernized engine technology, GPS-based control, and communication systems (BRTS, online).

Further division of responsibilities and maintenance mark an essential aspect in overall management scenario. But issues related to reinventing and evolving into a new institutional framework has not been attended. Improvisation concerning preparing backup infrastructure, public awareness program is only found in a few cases in India like Jamnagar BRTS. Hence remodeling Institutional support and responsibilities has become a necessity.

\section{A typical case of BRTS implementation in an Indian city - Raipur}

Due to immense urbanization and migration, traffic and transportation issues have reached its maximum limit in Raipur, the capital of Chhattisgarh. Raipur city had a population of 10,27,264 in 2011, the regions decadal growth rate of population was $34 \%$. Raipur district population constituted $16 \%$ of Chhattisgarh's total population. Central business districts (CBDs) have continued to prosper and grow in ways that require more transport capacity and improved access. Being a capital city it requires the implementation of a good and efficient Public Transportation system. Given the cost and environmental impacts associated with parking and road construction, expanded public transport emerges as an important alternative for providing that capacity. The land use of Raipur City is characterized by different hierarchical spatial levels: regional and sub-regional.

Analysis was carried out to identify major sub arterial and arterial roads in Raipur out of which Potential BRTS corridor was identified depending upon the available ROW, PCU, Road Capacity, V/C Ratio, Major Activities and communication. Analysis was also carried out on the different lane sections to verify the amount of space required for the BRT corridor and the available space for the mixed traffic and basic street components such as footpaths, cycle tracks, parking and dividers. Thus, existing lane sections were analyzed so as to study the existing road components, provision of facilities and pedestrian amenities.

Analysis of the corridor on aforementioned attributes along with environmental concern, social and cultural practices, available infrastructure, manpower for operation control, available economy, finances and political administration lead us to the conclusion that BRTS is an adequately viable option for the city of Raipur, India. 


\section{Prioritizing attributes for Raipur}

Few Indian cities having BRTS facilities have various levels of success in running the system. Few Indian cities like Raipur are on the anvil of promoting an absolutely new system of BRTS.

The attributes discussed in the initial sections were divided into "Service Quality Attributes" and "Auxiliary Attributes" through survey. An Expert Opinion Survey was conducted in Raipur on a calculated percentage of around $5 \%$ consisting of 445 samples with a confidence level of 95\% firstly to identify "Service Quality Attributes" and "Auxiliary Attributes" and then to prioritize the "Service Quality Attributes". The respondents were asked questions on a five-point Likert scale varying from a score range of 1 to 5 indicating "Strongly disagree (1); Disagree (2); Neither agree nor disagree (3); Agree (4); Strongly agree (5);" to identify the "Service Quality Attributes" (see in Figs. 1 and 2). The respondents for the Expert Opinion Survey included various planners, architects, engineers, administrators of various organizations as well as the commuters.

The selected corridor of Raipur for BRTS implementation is shown in Fig. 3. Survey was carried out on sample stakeholders of the selected corridor. Based on the results of the survey and the values assigned to each of the attributes by the respondents, a Correlation was established using Pearson's formula as shown in Table 2. In the correlation, "Social acceptance" data was used as independent variable to establish the degree of relationship with twenty-seven attributes. This correlation established the "Service Quality Attributes" as per Expert Opinion.

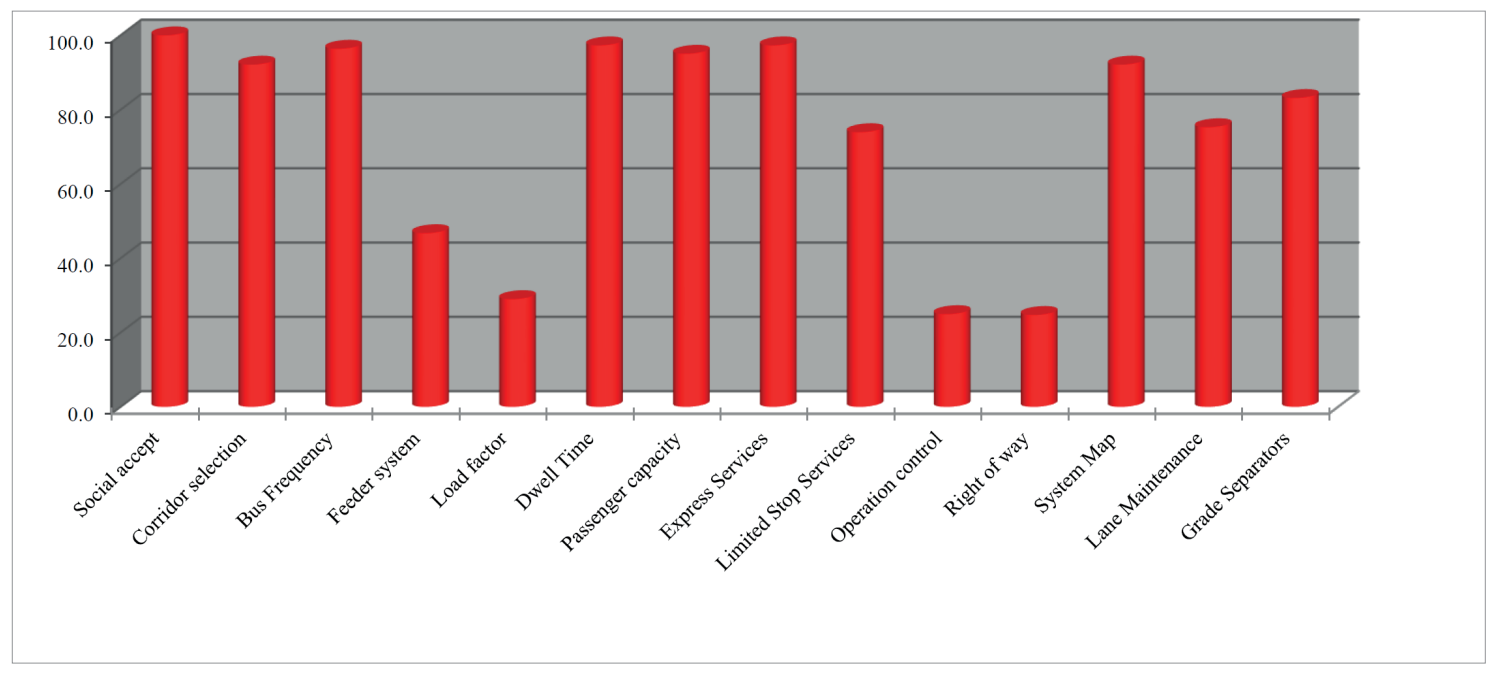

Fig. 1 Percentage of respondents with choice 4 \& 5 in the Likert Scale in selected Service Quality Parameters

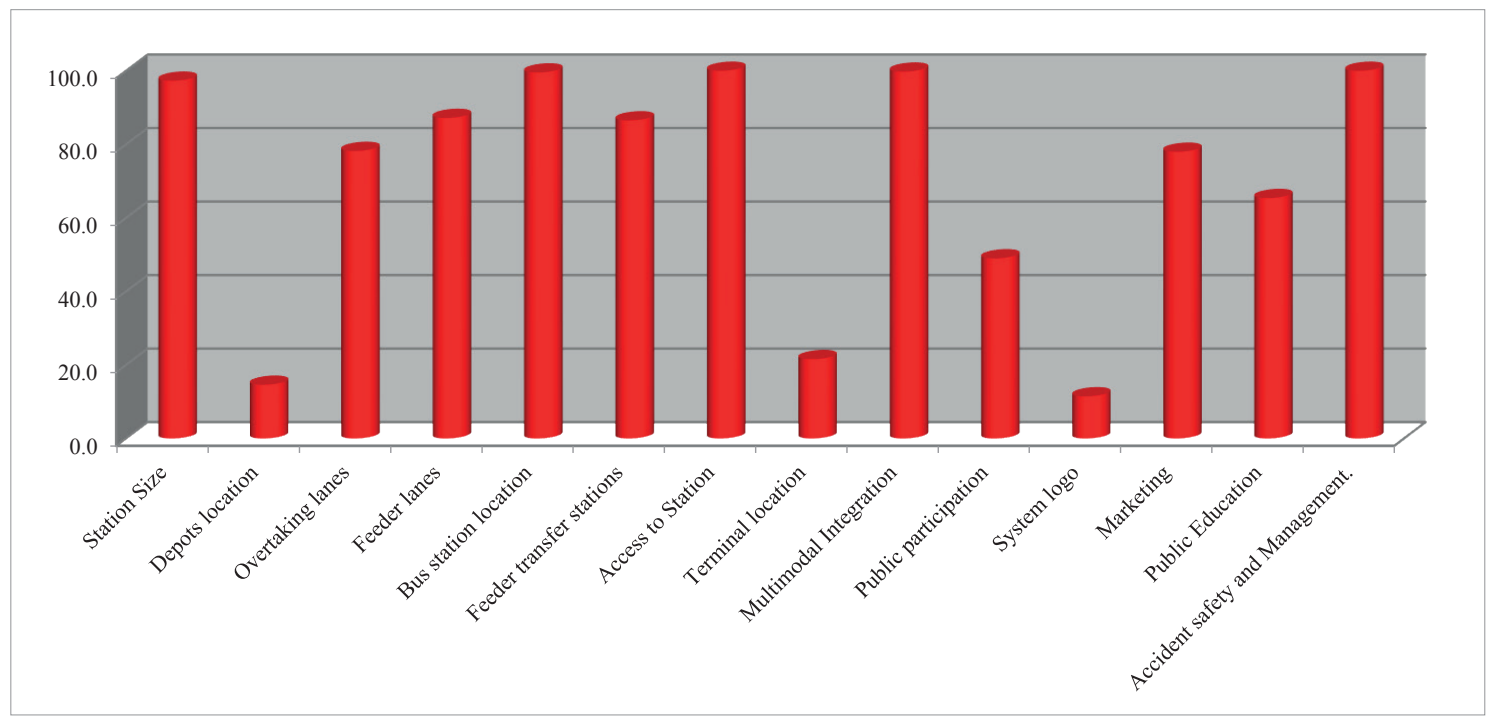

Fig. 2 Percentage of respondents with choice $4 \& 5$ in the Likert Scale in rest of the Service Quality Parameters 


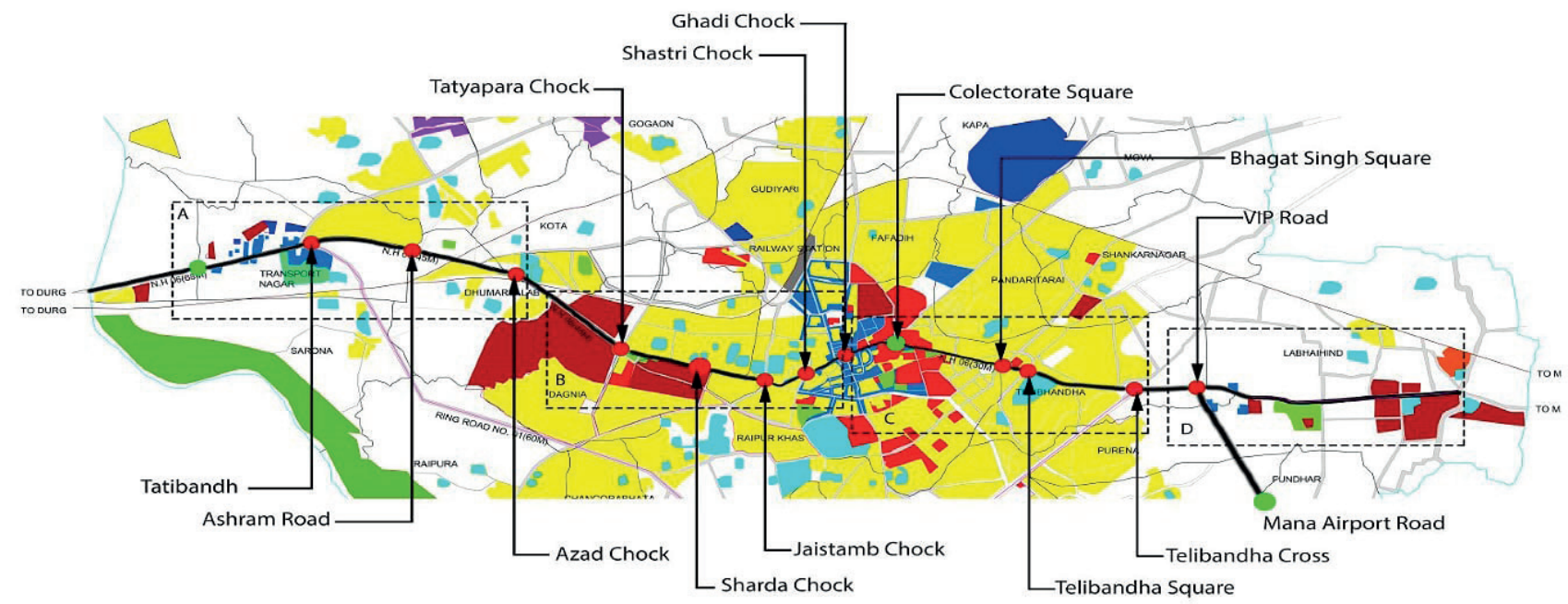

Fig. 3 The selected Corridor for BRTS implementation in Raipur (source: Raipur Development Authority data 2018)

Table 2 Correlation values $(r)$ of attributes

\begin{tabular}{|c|c|c|}
\hline Sr. no & Attributes & Values \\
\hline 1 & Corridor selection & 0.986 \\
\hline 2 & Bus frequency & 0.941 \\
\hline 3 & Feeder system & 0.744 \\
\hline 4 & Load factor & 0.531 \\
\hline 5 & Dwell time & 0.963 \\
\hline 6 & Passenger capacity & 0.973 \\
\hline 7 & Express services & 0.996 \\
\hline 8 & Limited Stop Services & 0.905 \\
\hline 9 & Operation control & -0.141 \\
\hline 10 & Right of way & 0.013 \\
\hline 11 & System map & 0.987 \\
\hline 12 & Lane maintenance & 0.879 \\
\hline 13 & Grade separators & 0.861 \\
\hline 14 & Station size & 0.975 \\
\hline 15 & Depots location & -0.424 \\
\hline 16 & Overtaking lanes & 0.788 \\
\hline 17 & Feeder lanes & 0.928 \\
\hline 18 & Bus station location & 0.989 \\
\hline 19 & Feeder transfer stations & 0.929 \\
\hline 20 & Access to station & 0.987 \\
\hline 21 & Terminal location & -0.087 \\
\hline 22 & Multimodal integration & 0.986 \\
\hline 23 & Public participation & 0.718 \\
\hline 24 & System logo & -0.334 \\
\hline 25 & Marketing & 0.792 \\
\hline 26 & Public education & 0.920 \\
\hline 27 & Accident Safety and Management. & 0.967 \\
\hline
\end{tabular}

Assimilating from the graphical representation (Figs. 1 and 2) and Table 2, the following attributes are identified as "Service Quality Attributes":
- Corridor selection;

- Bus frequency;

- Feeder system;

- Passenger capacity; dwell time;

- Passenger capacity, express services;

- Limited Stop Services;

- System map;

- Lane maintenance;

- Grade separators;

- Station size;

- Overtaking lanes;

- Feeder lanes;

- Bus station location;

- Feeder transfer station;

- Access to station;

- Multimodal integration;

- Public participation;

- Marketing;

- Public education;

- and Accident safety and Management.

Twenty-one attributes listed above have very high correlation value of 0.6 and above with Social acceptance.

Further investigation into research consisted of analyzing the "Level of significance" (P-value) for linear optimization using regression analysis. The attributes with high correlation values were optimized to understand how value of an attribute changes with the change of character of the independent attribute. The regression was done using the formula $Y=a+b X$ where $Y$ is the dependent attribute and $X$ is the independent attribute, ' $a$ ' and ' $b$ ' are constants. "Social acceptance" data was used as independent variable to establish the P-value. 
Table 3 Level of Significance of "Service Quality Attributes" using Linear regression

\begin{tabular}{|c|c|c|}
\hline Sr. no. & Attributes & P-value \\
\hline 1 & Corridor selection & 0.771 \\
\hline 2 & Bus Frequency & 0.72 \\
\hline 3 & Feeder system & 0.22 \\
\hline 4 & Dwell Time & 0.78 \\
\hline 5 & Passenger capacity & 0.762 \\
\hline 6 & Express Services & 0.927 \\
\hline 7 & Limited Stop Services & 0.57 \\
\hline 8 & System Map & 0.8 \\
\hline 9 & Lane Maintenance & 0.67 \\
\hline 10 & Grade Separators & 0.7 \\
\hline 11 & Station Size & 0.82 \\
\hline 12 & Overtaking lanes & 0.71 \\
\hline 13 & Feeder lanes & 0.71 \\
\hline 14 & Bus station location & 0.91 \\
\hline 15 & Feeder transfer stations & 0.83 \\
\hline 16 & Access to Station & 0.93 \\
\hline 17 & Multimodal Integration & 0.9 \\
\hline 18 & Public participation & 0.831 \\
\hline 19 & Marketing & 0.64 \\
\hline 20 & Public Education & 0.34 \\
\hline 21 & Accident safety and Management & 0.854 \\
\hline
\end{tabular}

The P-values shown in Table 3 suggest that except for Feeder system, Limited Stop Services, Lane maintenance and Public education, all other attributes command a very high level of Significance with Social acceptance. This further suggests that in typical Indian cities, Level of services of a BRTS is intrinsically associated with most of the attributes.

The research entails ranking of the attributes. To this end, a machine learning user-friendly interface called "Weka" was used. These attributes were ranked using the ReliefF Ranking filter (Kononenko et al., 1997). This unique filter method approach to feature selection is characterized by feature interaction. The features in each data set were awarded a feature score by the Releif Filter which was associated with a rank. The weighted score is based on an algorithm where a feature vector and the instance of closest 'nearHit' or 'nearMiss' with closest class is calculated using the formula:

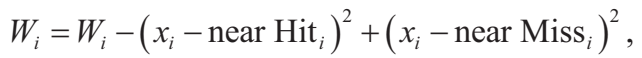

where $W$ is the 'Weighted score' and $x$ is the 'Feature vector'. In this research, attributes are the feature vectors.
Table 4 Ranking of "Service Quality Attributes" using Relief Ranking Filter

\begin{tabular}{|c|c|c|c|}
\hline Sr. No & Attributes & Score & Rank \\
\hline 1 & Express Service & 0.6986 & 1 \\
\hline 2 & Bus Station Location & 0.6863 & 2 \\
\hline 3 & Access to Station & 0.6849 & 3 \\
\hline 4 & Multimodal Integration & 0.6828 & 4 \\
\hline 5 & System Map & 0.6800 & 5 \\
\hline 6 & Corridor Selection & 0.6796 & 6 \\
\hline 7 & Station Size & 0.6692 & 7 \\
\hline 8 & Passenger Capacity & 0.6661 & 8 \\
\hline 9 & Dwell Time & 0.6590 & 9 \\
\hline 10 & Bus Frequency & 0.6426 & 10 \\
\hline 11 & Accident Safety and Management & 0.6359 & 11 \\
\hline 12 & Feeder Transfer Station & 0.6310 & 12 \\
\hline 13 & Feeder lanes & 0.6307 & 13 \\
\hline 14 & Express Services & 0.6135 & 14 \\
\hline 15 & Grade Separator & 0.5920 & 15 \\
\hline 16 & Overtaking lanes & 0.5554 & 16 \\
\hline 17 & Public participation & 0.5405 & 17 \\
\hline 18 & Load Factor & 0.5319 & 18 \\
\hline 19 & Feeder system & 0.1933 & 19 \\
\hline 20 & Public Education & 0.0409 & 20 \\
\hline 21 & Marketing & 0.0204 & 21 \\
\hline
\end{tabular}

The scoresin Table 4 indicate the hierarchy of importance of each "Service Quality Attributes", for the operation of BRTS in a typical Indian city as is the case of Raipur.

\section{Recommendations for Raipur}

The proposed corridor is divided into 3 sections A, B and $\mathrm{C}$ depending upon the available ROW. Section $\mathrm{A}$ has width of $60 \mathrm{~m}$, Section B has width of $36 \mathrm{~m}$ and Section C has $30 \mathrm{~m}$. The lane properties were analyzed for Average PCU, Average Road Capacity, Average V/C and Major intersections. Based on the analysis, ranking and optimization of attributes, the proposals are directed to:

1. Integrating existing transit of Raipur with the new BRTS systems by providing interchange points at major stations with other feeder transit systems;

2. Mapping of BRTS stations on the main trunk corridor and connection to different feeder lines;

3. Design of BRTS stations, night parking and terminals with respect to Universal accessibility;

4. Design and planning of cycle integration at BRTS station and terminals for sustainable non-motorized transit; 
5. Design and planning of BRTS depots with respect to decrease Dead miles for the services at the time of start and end of services;

6. Design and planning of BRTS depots and night parking with respect to decrease Dead miles for the services at the time of start and end of services;

7. Design and provision of pedestrian facilities such as road crossings, pedestrian signals. Elevated road crossings on high density traffic zones;

8. Design and provision of refuge islands, curbs, ramps;

9. Design and planning of Overtaking lanes at some stations to facilitate Limited Stop Services;

10. Planning of Information Technology Services (ITS) in the street intersections to provide efficient traffic information and systemized timing of traffic lights to efficiently control the flow of traffic;

11. Planning of uniform Frequency for feeder systems to enable fast interchange and lower travel and waiting time;

12. Planning appropriate Frequency for services depending upon the demands and ridership;

13. Planning a Centralized Control for BRTS services to control the headway depending upon the corridor traffic, delays and blockages;

14. Planning of Intelligent Transport System in the corridor and the stations for efficient operation of the buses and passenger information.

\section{Conclusion}

BRTS today is characterized by services in 174 cities worldwide, conveying 32 million passengers over a network of more than $5000 \mathrm{~km}$ (BRTS, online). India currently has 27 million-plus cities (Office of the Registrar General \& Census Commissioner, India, 2011) with ever-increasing vehicle ownership ratio, pollution, and continuously decreasing road space per-capita. Many of these Indian cities do not

\section{References}

Abdelghany, K. F., Mahmassani, H. S., Abdelghany, A. F. (2007) "A Modeling Framework for Bus Rapid Transit Operations Evaluation and Service Planning", Transportation Planning and Technology, 30(6), pp. 571-591. https://doi.org/10.1080/03081060701698219

Bitterman, A., Hess, D. B. (2008) "Bus rapid transit identity meets universal design", Disability \& Society, 23(5), pp. 445-459. https://doi.org/10.1080/09687590802177015

BRTS "Cross system indicators" [online] http://BRTSdata.org [Accessed: 12 October 2017]

BRTS "The BRT Standard" [online] http://www.itdp.org/index.php/ microsite/BRTS_planning_guide [Accessed: 05 January 2018] have an efficient public transit system that is considered safe and reliable and have embarked on BRTS. BRTS stands as a relatively low-cost, flexible, environment-friendly solution to the ever-deepening crisis. With designed BRTS corridor, proper benefaction of system capacity, state of the art system management and control, bus stations, feeder transfer solutions maintenance, and accident preparedness, BRTS can be implemented in Indian cities, where it is lacking. It will help in upgrading the image of public transport as segregated bus bays reduce travel time and dwell time. It will help to reduce the overall travel time of the passengers. Communications, including public education, participation, and marketing, hold a pivotal role in shaping the new public transit and Indian cities.

Many authors (Hidalgo and Bhatt, 2015) tried to draw parallels with the failure of Delhi BRTS. However, its failure may be debated upon as technical reports by World Resource Institute (WRI) India, EMBARQ, and CST India established that the system although it had implementation flaws could provide better mobility to the users. The Delhi BRTS has provided learning lessons of dos and don'ts in the proper implementation of a BRTS. In Indian conditions, the validation above, establishes the relative importance of various attributes in a BRTS design and implementation. The successful BRTS must combine suitable station design, track design, maintained vehicles and running ways with backup infrastructure, educated and updated drivers and workforce, public cautiousness, and system backed information technology.

BRTS, thus designed strategically, will integrate existing or proposed traffic networks either with metros or even up to the last-mile mode of transport. With BRTS continually reinventing itself and evolving, the institutional framework needs revamping. The discussion shows appraisal based on which successful application of BRTS may be made in Indian conditions.

Cervero, R. (2013) "Bus Rapid Transit (BRT): An Efficient and Competitive Mode of Public Transport", [pdf] Institute of Urban and Regional Development, University of California, Berkeley, CA, USA. Available at: https://www.acea.be/uploads/publications/20th_SAG_HR.pdf [Accessed: 17 July 2017]

Cervero, R., Kang, C. D. (2011) "Bus rapid transit impacts on land uses and land values in Seoul, Korea", Transport Policy, 18(1), pp. 102-116. https://doi.org/10.1016/j.tranpol.2010.06.005

Deng, T., Nelson, J. D. (2011) "Recent Developments in Bus Rapid Transit: A Review of the Literature", Transport Reviews, 31(1), pp. 69-96. https://doi.org/10.1080/01441647.2010.492455 
Duduta, N., Adriazola, C., Wass, C., Hidalgo, D., Lindau, L. A. (2012) "Traffic Safety on Bus Corridors: Guidelines for integrating pedestrian and traffic safety into the planning, design, and operation of BRT, Busways and bus lanes - Pilot Version - Road Test", [pdf] EMBARQ, Washington, DC, USA. Available at: https://www. embarq.org/sites/default/files/EMB2012_Traffic_Safety_on_Bus_ Corridors_Pilot_Version.pdf [Accessed: 15 July 2017]

Economic Research Institute for ASEAN and East Asia (ERIA) (2013) "An Overview of Bus Rapid Transits in the World, in Improving Energy Efficiency in the Transport Sector through Smart Development", [pdf] In: Kutani, I. (ed.) Improving Energy Efficiency in the Transport Sector through Smart Development, ERIA Research Project Report 2013-27, Jakarta, Indonesia, pp. 5-25. Available at: http:/www.eria.org/RPR_FY2013 No.27_Chapter_2.pdf [Accessed: 20 July 2017]

Gandhi, S., Tiwari, G., Fazio, J. (2013) "Comparative Evaluation of Alternate Bus Rapid Transit System (BRTS) Planning, Operation and Design Options", Journal of the Eastern Asia Society for Transportation Studies, 10, pp. 1292-1310. https://doi.org/10.11175/easts.10.1292

Garg, A., Shukla, P. R., Kankal, B., Mahapatra, D. (2017) "CO2 emission in India: trends and management at sectoral, sub-regional and plant levels", Carbon Management, 8(2), pp. 111-123. https://doi.org/10.1080/17583004.2017.1306406

Gautam, I. P., Swamy, H. M. S., Lokre, A., Arya, V. (2014) "Innovations in Design: Ahmedabad Bus Rapid Transit System", Centre of Excellence in Urban Transport, CEPT University, Mapin Publishing, Ahmedabad, India.

Godavarthi, G. R., Chalumuri, R. S., Velmurugun, S. (2014) "Measuring the Performance of Bus Rapid-Transit Corridors Based on Volume by Capacity Ratio", Journal of Transportation Engineering, 140(10), Article ID: 04014049. https://doi.org/10.1061/(ASCE)TE.1943-5436.0000698

Hidalgo, D., Lleras, G., Hernández, E. (2013) "Methodology for calculating passenger capacity in bus rapid transit systems: Application to the TransMilenio system in Bogotá, Colombia", Research in Transportation Economics, 39(1), pp. 139-142. https://doi.org/10.1016/j.retrec.2012.06.006

Hidalgo, D., Muñoz, J. C. (2014) "A review of technological improvements in bus rapid transit (BRT) and buses with high level of service (BHLS)", Public Transport, 6(3), pp. 185-213. https://doi.org/10.1007/s12469-014-0089-9

Hidalgo, D., Bhatt, A. (2015) "Don’t Miss the Bus, Delhi", The Hindu Business Line, [online] 14 August 2015. Available at: https://www. thehindubusinessline.com/blink/know/dont-miss-the-bus-delhi/ article7508049.ece [Accessed: 25 January 2018]

Imam, R. (2012) "Energy Consumption and Environmental Impacts of Bus Rapid Transit (BRTS) Systems", Jordan Journal of Civil Engineering, 6(3), pp. 328-339.

Institute of Transportation and Development Policy (ITDP) (2017) "Bus Rapid Transit Planning Guide", Institute of Transportation and Development Policy, New York, NY, USA. [online] Available at: https://www.itdp.org/2017/11/16/the-BRTS-planning-guide/ [Accessed: 20 January 2018]

Jiang, Y., Zegras, P. C., Mehndiratta, S. (2012) "Walk the line: Station context, corridor type and bus rapid transit walk access in Jinan, China", Journal of Transport Geography, 20(1), pp. 1-14. https://doi.org/10.1016/j.jtrangeo.2011.09.007
Kathuria, A., Parida, M., Sekhar, C. R., Sharma, A. (2016) "A review of bus rapid transit implementation in India", Cogent Engineering, 3(1), Article number: 1241168 https://doi.org/10.1080/23311916.2016.1241168

Kathuria, A., Parida, M., Sekhar, C. R. (2017) "Route performance evaluation of a closed bus rapid transit system using GPS data", Current Science, 112(8), pp. 1642-1652. https://doi.org/10.18520/cs/v112/i08/1642-1652

Kononenko, I., Šimec, E., Robnik-Šikonja, M. (1997) "Overcoming the Myopia of Inductive Learning Algorithms with RELIEFF", Applied Intelligence, 7(1), pp. 39-55. https://doi.org/10.1023/A:1008280620621

Kumara, H. S. (2009) "Planning for Bus Rapid Transit System (BRTSS) in Indian Metropolitan Cities: Challenges and options", [pdf] Institute of Town Planners, India Journal, 6(4), pp. 9-21. http://itpi. org.in/pdfs/oct2_09.pdf [Accessed 01 February 2018]

Levinson, H. S., Zimmerman, S., Clinger, J., Gast, J., Rutherford, S., Bruhn, E. (2003) "TCRP Report 90: Bus Rapid Transit: Volume 2: Implementation Guidelines", Transportation Research Board, Washington, DC, USA, Rep. 90. [online] Available at: https://nacto. org/docs/usdg/tcrp_rpt_90_implementation_guidelines_volume_2 levinson.pdf [Accessed: 28 January 2018]

Li, F., Duan, Z., Yang, D. (2012) "Dwell time estimation models for bus rapid transit stations", Journal of Modern Transportation, 20(3), pp. $168-177$. https://doi.org/10.1007/BF03325795

Muhammad, A. A., Ishak, N., Ibrahim, F. A., I., Razak, S. M. S. A., Rahim, M. M. A. (2016) "Implementation of Systematic Public Transportation in Malaysia: Development of Bus Rapid Transit", In: International Conference on Transportation, Civil and Architectural Engineering, London, UK, pp. 121-123.), [online] Available at: https://www. researchgate.net/publication/304334872_Implementation_of Systematic_Public_Transportation_in_Malaysia_Development_of Bus_Rapid_Transit [Accessed: 30 January 2018]

Nikitas, A., Karlsson, M. (2015) "A Worldwide State-of-the-Art Analysis for Bus Rapid Transit: Looking for the Success Formula", Journal of Public Transportation, 18(1), pp. 1-33. http://doi.org/10.5038/2375-0901.18.1.3

Office of the Registrar General \& Census Commissioner, India "2011 Census Data" [online] https://censusindia.gov.in/2011-Common/ CensusData2011.html [Accessed: 17 October 2017]

Satiennam, T., Fukuda, A., Oshima, R. (2006) "A Study of the Introduction of Bus Rapid Transit System in Asian Developing Cities: A Case Study of Bangkok Metropolitan Administration Project", IATSS Research, 30(2), pp. 59-69. https://doi.org/10.1016/S0386-1112(14)60170-9

Sharul, A. (2014) "Update on BRTS initiatives in Malaysia. Quantifying the environmental, social, and economic benefits from Bus Rapid Transit (BRTS) Systems", SPAD Academy \& ASIA LEDS Partnership Workshop, Yogyakarta, Indonesia. [online] Available at: http://www.asialeds.org/resource/update-on-BRTS-initiativesin-malaysia/ [Accessed: 20 February 2018]

Swamy, S. (2014) "CEPT Centre of excellence in Urban Transport Janmarg BRTSS", [pdf] Ahmedabad Bus Rapid Transit System, Ahmedabad, India. www.unescap.org/sites/default/files/4.2\%20Institutional $\% 20$ issues $\% 20$ and $\% 20$ coordination $\% 20 \mathrm{in} \% 20$ sustainable $\% 20$ transport\%20-\%20CEPT.pdf> [Accessed: 21 March 2018] 
Tann, H. M., Hinebaugh, D. (2009) "Characteristics of Bus Rapid Transit for Decision Making", [pdf] Federal Transit Administration and U.S. Department of Transportation, Washington, DC, USA, Rep. FTAFL-26-7109.2009.1. Available at: https://www.transit.dot.gov/sites/ fta.dot.gov/files/CBRT_2009_Update.pdf [Accessed 17 July 2017]

Transportation Research Board and National Academies of Sciences, Engineering, and Medicine (2013) "Transit Capacity and Quality of Service Manual, Third edition", The National Academies Press, Washington, DC, USA.

https://doi.org/10.17226/24766

Transportation Systems Engineering Group (TSEG) (2014) "Report on Road Safety Audit of Pilot BRTSS Corridor at Pune", Department of Civil Engineering Indian Institute of Technology Bombay, Powai, Mumbai, Rep. XX. [online] Available at: https://pmc.gov.in/informpdf/BRTSS/Safety_Audit_Report.pdf [Accessed: 10 January 2018]
Tsao, H. S. J., Wei, W., Pratama, A. (2009) "Operational feasibility of one-dedicated-lane bus rapid transit/light rail systems", Transportation Planning and Technology, 32(3), pp. 239-260. https://oi.org/10.1080/03081060903017085

World Health Organization (WHO) (2015) "Global Status Report on Road Safety 2015", World Health Organization (WHO), Geneva, Switzerland. Rep. XX. https://www.who.int/violence_injury_prevention/road_safety_status/2015/en/ [Accessed: 15 January 2018]

Wright, L., Hook, W. (2007) "Bus Rapid Transit Planning Guide", Institute for Transportation \& Development Policy, New York, NY, USA.

Zou, P., Li, Z., Li, M. (2012) "Real-time Arterial Performance Measurement Using BRT Probe Data and Signal Timing Data", Journal of Transportation Systems Engineering and Information Technology, 12(3), pp. 24-30.

https://doi.org/10.1016/S1570-6672(11)60201-8 